\title{
PRELÚDIOS ACERCA DA LEITURA E A FORMAÇÃO DO SUJEITO
}

\section{PREFERRED ABOUT READING AND THE FORMATION OF THE SUBJECT}

\author{
Gislene de Sousa Oliveira Silva - Seduce Goiás/ UFG-Catalão/Brasil \\ Selma Martines Peres - UFG-Catalão/Brasil
}

\begin{abstract}
RESUMO: O objetivo deste artigo é discutir acerca do que pensam alguns autores sobre leitura, formação do leitor, leitura literária, para efetiva participação do sujeito, em sociedade. Esta proposta surgiu a partir de reflexões sobre algumas das principais teorias de pesquisadores da área, acerca da formação do leitor, desde as séries iniciais, e a relevância e necessidade do trabalho, cada vez mais cuidadoso e reflexivo com a leitura, para formação do sujeito e seu empoderamento, considerando ainda a leitura literária como parte essencial neste processo. Adotou-se como metodologia, a pesquisa bibliográfica, por meio da abordagem de autores que discutem acerca da temática apresentada. É discutido sobre a leitura como processo de conscientização do indivíduo e importância de posicionamento como sujeito na construção do seu próprio conhecimento. Para tal, faz-se necessário a mudança de postura do leitor perante o texto. De mero decifrador de códigos para sujeito que interage, participa, questiona e dialoga, na construção de sentidos, a partir do que lê. Assim também, a mudança de postura do formador, como fator imprescindível para o trabalho de formação do sujeito leitor, considerando a diversidade de gêneros textuais e a leitura literária. Neste trabalho, houve um diálogo com autores que discutem sobre leitura, formação de leitor e leitura literária. Espera-se que este diálogo suscite outras reflexões e contribua para novos estudos sobre o tema.
\end{abstract}

Palavras-chave: Formação de leitor. Leitura. Leitura literária.

ABSTRACT: The aim of this article is to discuss what some authors think about reading, reader formation, literary reading, for the effective participation of the subject in society. This proposal arose from reflections on some of the main theories of researchers in the area, about the reader's formation, from the early grades, and the relevance and necessity of the work, increasingly careful and reflective with reading, for the subject's formation. and its empowerment, considering literary reading as an essential part of this process. It was adopted as methodology, the bibliographic research, through the approach of authors who discuss about the presented theme. It is discussed about reading as a process of awareness of the individual and the importance of positioning as a subject in the construction of their own knowledge. For this, it is necessary to change the reader's attitude towards the text. From a simple code decipherer to a subject who interacts, participates, questions and dialogues, in the construction of meanings, from what he reads. Also, the change of attitude of the trainer, as an essential factor for the work of formation of the reader subject, considering the diversity of textual genres and literary reading. In this paper, there was a dialogue with authors who discuss reading, reader training and literary reading. It is hoped that this dialogue will raise further reflections and contribute to further studies on the subject.

Keywords: Reader training. Reading. Literary reading.

Educação, Psicologia e Interfaces, Volume 3, Número 1, p. 43-60, Janeiro/Abril, 2019.

ISSN: 2594-5343. DOI: https://doi.org/10.37444//issn-2594-5343.v3i1.140 


\title{
1. INTRODUÇÃO
}

Para este artigo, foi realizada uma revisão bibliográfica com o intuito de compreender o que pensam alguns autores acerca da leitura, formação do leitor, leitura literária, para efetiva participação do sujeito, em sociedade. Esta proposta surgiu a partir de reflexões sobre algumas das principais teorias de pesquisadores da área, acerca da formação do leitor, desde as séries iniciais, e a relevância e necessidade do trabalho, cada vez mais cuidadoso e reflexivo com a leitura, para formação do sujeito e seu empoderamento.

Silva (1996) ressalta que a leitura não pode ser vista como apenas um processo de decodificação de sinais e/ou ação mecanizada. Segundo ele, "esta confusão nada mais faz do que decretar a morte do leitor, transformando-o num consumidor passivo [...]" (SILVA, 1996, p.96). Nessa perspectiva, Martins (1994, p. 33) conceitua que a leitura perpassa o texto, iniciando mesmo antes do contato com ele.

\begin{abstract}
A leitura se realiza a partir do diálogo do leitor com o objeto lido - seja escrito, sonoro, seja um gesto, uma imagem, um acontecimento. Esse diálogo é referenciado por um tempo e um espaço, uma situação; desenvolvido de acordo com os desafios e as respostas que o objeto apresenta, em função de expectativas e necessidades, do prazer das descobertas e do reconhecimento de vivências do leitor (MARTINS, 1994, p. 33).
\end{abstract}

Sendo assim, o leitor, de maneira alguma tem postura passiva diante do que lê. Pelo contrário, de acordo com a autora, o diálogo é imprescindível entre o leitor e o objeto de leitura. E este contato é permeado por situações vivenciadas pelo indivíduo, ao longo de sua vida.

De acordo com Silva (1996, p.95), "o ato de ler é uma necessidade concreta para a aquisição de significados [...]. Inicia-se quando um sujeito, através de sua percepção, toma consciência de documentos escritos no mundo." O autor ainda ressalta que a leitura se manifesta, então, como a experiência resultante do trajeto seguido pela consciência do sujeito em seu projeto de desvelamento do texto. É essa mesma experiência (ou vivência dos horizontes desvelados através do texto) que vai permitir a emergência de ser leitor. "Por sua vez, os novos significados apreendidos na experiência do leitor fazem com que este se posicione em relação ao documento lido" (SILVA, 1996, p. 95).

Educação, Psicologia e Interfaces, Volume 3, Número 1, p. 43-60, Janeiro/Abril, 2019. 
Conforme o autor, é essencial que o sujeito, para produzir significados, interaja com o texto, pois "A riqueza maior de um texto é sua capacidade de evocar múltiplos sentidos entre os leitores" (SILVA, 1999, p.16). Relevante destacar que, dessa maneira, cada leitor constrói sentidos em relação a um mesmo texto, pois “o texto age sobre o leitor e, retrodinamicamente, o leitor age sobre o texto" (SILVA, 1999, p.16).

Dessa maneira, a responsabilidade de quem trabalha com a leitura é, principalmente a formação do senso crítico do leitor e isto exige que, primeiramente, a postura de quem auxilia na formação do leitor, seja crítica e consciente das relações sociais e do indivíduo.

O objetivo desse artigo é discutir acerca do que pensam alguns autores sobre leitura, formação do leitor, leitura literária, para efetiva participação do sujeito, em sociedade. Adotou-se como metodologia, a pesquisa bibliográfica, por meio da abordagem de autores que discutem sobre leitura, formação de leitor e leitura literária. Dentre eles, Freire (1989); Martins (1994); Evangelista (1998); Silva (1996; 1999); Britto (1999; 2012); Machado (2002); Soares(2000; 2004; 2008; 2011); Paulino e Cosson (2009); Zilberman (2003;2009); Cosson (2006; 2014); Chartier (2011); Geraldi (2012); Certeau (2014); e outros.

\section{LEITURA E A FORMAÇÃO DO SUJEITO}

A formação do leitor tem se tornado uma grande preocupação que ultrapassa o cotidiano escolar, mesmo a escola sendo responsabilizada por esta função. De acordo com Freire (1989, p. 35) a "leitura do mundo precede a leitura da palavra". A leitura de mundo, de acordo com o autor se dá por meio de descobertas, vivências, curiosidades, busca pela percepção e compreensão de mundo, pelo sujeito. Sendo assim, esta percepção, torna-se requisito essencial para a leitura da palavra. Nesse sentido, o autor destaca a leitura de mundo dele, quando criança, em que,

A decifração da palavra fluía naturalmente da 'leitura' do mundo particular. Não era algo que se estivesse dando supostamente a ele. Fui alfabetizado no chão do quintal de minha casa, à sombra das mangueiras, com palavras do meu mundo e não do mundo maior dos meus pais. $\mathrm{O}$ chão foi o meu quadro-negro; gravetos, o meu giz. (FREIRE, 1989, p. 35).

Educação, Psicologia e Interfaces, Volume 3, Número 1, p. 43-60, Janeiro/Abril, 2019.

ISSN: 2594-5343. DOI: https://doi.org/10.37444//issn-2594-5343.v3i1.140 
O autor ressalta ainda, o caráter político da leitura do mundo e da palavra, em que é imprescindível a compreensão/interpretação do que se vê, se faz, se pensa e repensa, a postura, a atitude e ação do sujeito. A partir disto fica evidente papel essencial da leitura, desde os primeiros contatos do indivíduo, com o mundo, com as letras, com a escrita, para futura participação em sociedade.

Britto (2012) corrobora com estas afirmativas quanto ressalta que, quanto mais o indivíduo se conhece e conhece as necessidades que o mundo lhe cobra, o porquê, o para quê se lê, mais se intensifica e aumenta o seu grau de conscientização de ser pensante e crítico na sociedade. E mais, em relação à questão de hábito de ler e gosto, o autor instiga a pensar sobre a afirmativa, que o desinteresse pela leitura resulta do caráter autoritário imposto na formação de leitores. Segundo ele, a leitura vista apenas como ato prazeroso e agradável, não difere de outras formas de consumo de massa, qual sejam, programas de televisão; cinema de entretenimento, e, justamente por isso, deixa de contribuir para a experiência formativa. Acrescenta ainda que,

\begin{abstract}
A leitura fácil e apoiada no senso comum (difundidas pelos sistemas ideológicos e pela lógica da normatividade produtiva) não estimula a indagação da condição humana nem a crítica e as criatividades desimpedidas. Antes, mantém a pessoa na alienação e na submissão ao que se estabeleceu desde outro lugar, oferecendo-lhe a falsa ilusão de crescimento (BRITTO, 2012, p. 45).
\end{abstract}

Em consonância com Freire (1989), o autor reafirma a importância da leitura como um ato de posicionamento político diante do mundo onde, quanto mais o sujeito adquire consciência desse processo, mais independente será sua leitura. Porém deixa claro que, quesito inerente à leitura, é constitutivo do processo mesmo que não seja percebido o caráter político do ato de ler. Através da leitura, que não seja somente a de entretenimento (com suas facilidades e prazeres), o leitor reflete sobre sua existência (dele), questiona o mundo e posiciona-se. Por isso, segundo o autor o relevante papel da leitura para acesso aos bens de cultura letrada e aos códigos e valores inscritos no mundo. E ainda, para a participação social efetiva. Daí sua crítica a campanhas de incentivo à leitura, no Brasil quando incentivam a leitura como algo puramente prazeroso:

É representativa desse movimento de valorização da leitura do prazer a campanha de incentivo à leitura promovida pelo Ministério da Educação em 1997, com o lema "quem lê, viaja"...) A leitura comparada a um narcótico ("quem lê, viaja"), nada tem a ver com a

Educação, Psicologia e Interfaces, Volume 3, Número 1, p. 43-60, Janeiro/Abril, 2019. 
construção de conhecimento ou com a experiência solidária e coletiva de crítica intelectual (BRITTO, 1999, p.86)

Britto critica e se posiciona contra esse tipo de definição para a leitura e o ato de ler. De acordo com ele, será leitor aquele indivíduo que, além da alfabetização e de certo domínio do código e de sua funcionalidade prática, estabeleça para si certa frequência de leitura, gostando ou não, tendo prazer ou não, para que possa construir seu próprio conhecimento, inserção na sociedade e ainda, acesso aos valores, sistemas de referência e processos de significação autorizados pelo discurso da escrita. E, claro, de forma crítica e também consciente que todo esse exercício exigirá dele um esforço intelectual, físico e de muita paciência, pois, não poderá ser em todo o momento, prazeroso e agradável. Para Soares (2000, p.48), ler inclui práticas sociais. Ler seria então:

Um conjunto de habilidades e comportamentos que se estendem desde simplesmente decodificar sílabas ou palavras até ler Grande Sertão Veredas de Guimarães Rosa... uma pessoa pode ser capaz de ler um bilhete, ou uma história em quadrinhos, e não ser capaz de ler um romance, um editorial de jornal... Assim, ler é um conjunto de habilidades, comportamentos, conhecimentos que compõem um longo e complexo continuum: em que ponto desse continuum uma pessoa pode ser considerada letrada, no que se refere à leitura? (SOARES, 2000, p. 48).

A afirmativa da autora vem acompanhada de reflexões acerca das condições de leitura e escrita, em que não há material impresso posto a disposição, não há livrarias, o preço dos livros e até dos jornais e revistas é inacessível, número muito pequeno de bibliotecas. Enfim, denuncia a precariedade das condições e oportunizadas para que os indivíduos tenham uma formação leitora. Esse posicionamento vem ao encontro do que já afirmava Silva (1996, p.46) acerca da necessidade de escolas e famílias brasileiras ter acesso ao livro, às melhores bibliotecas, dada a importância da leitura, na formação do sujeito. De acordo com o autor:

Leitura é um dos principais instrumentos que permite ao Ser Humano situar-se com os outros, de discussão e de crítica para se poder chegar à práxis. (O contexto da maioria das escolas nacionais ainda está longe de outros recursos de conscientização - a ciência e a cultura chegam às escolas através dos livros; negar isto é formar o modelo da escola ideal, mas não considerar concretamente as escolas) (SILVA, 1996, p. 46)

Mas o que significa ensinar a leitura? E é esta a pergunta que Britto (2012, p.43) faz e, de imediato destaca duas dimensões para o ensino da leitura: no âmbito do 


\section{Gislene de Sousa Oliveira Silva \& Selma Martines Peres}

alfabetismo básico, a saber, segundo o autor, o desenvolvimento do domínio do código escrito (decifração) para a realização de tarefas da vida diária em que o uso da escrita está pressuposto, onde a leitura contribua para que a pessoa participe apropriadamente do cotidiano urbano. E a dimensão do envolvimento com os produtos da cultura, qual seja, para a formação das pessoas, por meio da experiência e da vivência intensa, metódica e consistente com o conhecimento em suas diversas formas de expressão.

O autor ressalta que a leitura e o hábito de ler podem ser aprendidos, por meio do estímulo, de forma prática e dinâmica, e com o principal o propósito de incentivo ao conhecimento, pois, segundo ele, “[...] o conhecimento que promove a leitura” (BRITTO, 2012, p. 44).

A partir desses conceitos, é relevante pensar sobre a leitura e o papel da escola. E assim pode-se dizer que a escola enfrenta esse problema: o de apresentar a esses jovens, que leem, mas leem coisas diferentes do que a escola se propõe a provocar, leituras que, como diz Britto (2012, p. 95) vão além de atender à concepção de leitura como algo fácil. Segundo o autor, "a função da educação escolar é promover o senso crítico e os conhecimentos que ultrapassam a vida cotidiana. A formação do gosto se relaciona às experiências culturais e intelectuais, à inserção da pessoa num universo de relação complexas. O sujeito precisa aprender a encontrar satisfação no exercício intelectual e na ação disciplinada. Prazer, nesse cenário, não é o mesmo que lazer, mas é fruto de muito trabalho.

Dessa maneira, ressalta-se o importante papel da leitura literária, no espaço escolar. Sua prática tem sido objeto de estudos e reflexões, a respeito de como vem sendo trabalhada, principalmente em sala de aula, no que concerne às práticas pedagógicas docentes e da contribuição da literatura, no processo de formação leitora.

A leitura literária convive com inúmeros outros tipos de leitura, entre elas aquelas voltadas para as necessidades práticas da vida cotidiana como ler bilhetes, cartas, manifestos, artigos, notícias, etc., mas ela instaura um tipo de pacto com o leitor que a distancia das outras práticas sociais "letradas". "No contato do leitor com o texto literário, esse pacto se dá, via experiência estética, uma experiência na linguagem da invenção, do jogo simbólico que busca representar realidades não percebidas pela linguagem da comunicação usual, corriqueira." (MACHADO, 2002, p.71). Porém, de acordo com Soares (2011, p.22) é necessário se atentar para o fato de que a literatura é escolarizada

Educação, Psicologia e Interfaces, Volume 3, Número 1, p. 43-60, Janeiro/Abril, 2019. 
de forma inadequada, em que o livro literário é utilizado como mecanismo de discussão e aquisição de outros saberes escolares. Sendo assim,

\begin{abstract}
Não se deve negar a escolarização da literatura, mas a inadequada, a errônea, a imprópria escolarização da literatura, que se traduz em sua deturpação, falsificação, distorção, como resultado de uma pedagogização ou uma didatização mal compreendida que, ao transformar o literário em escolar, desfigura-o, desvirtua-o, falseia-o. É preciso lembrar que essa escolarização inadequada pode ocorrer não só com a literatura, mas também com outros conhecimentos (...) (SOARES, 2011, p.22).
\end{abstract}

No que concerne ao letramento literário, Paulino e Cosson (2009) discutem sobre a necessidade de defini-lo como o processo de apropriação da literatura enquanto construção literária de sentido. Segundo os autores, considerar o letramento literário um processo significa tomá-lo como um estado permanente de transformação, uma ação contínua, e não uma habilidade que se adquire como aprender a andar de bicicleta ou um conhecimento facilmente mensurável como a tabuada de cinco. Dessa forma, o letramento literário não começa nem termina na escola, mas é uma aprendizagem que acompanha o sujeito, em toda a sua formação leitora, a saber, por toda a vida, e ainda, que se renova a cada leitura de uma obra significativa.

Percebe-se a importância da leitura, porém, esta premissa instiga outro questionamento: “Ler, mas ler o quê?” (ZILBERMAN, 2009, p.29) Nos dizeres da autora, a escola, com a incumbência de ensinar a ler, tem interpretado essa tarefa de um modo mecânico e, através de exercícios, automatizam o uso da leitura. Dessa maneira,

o sentido da leitura nem sempre se esclarece para o aluno que é beneficiário dela. Por conseguinte, mesmo aprendendo a ler e conservando essa habilidade, a criança não se converte necessariamente em um leitor, já que este se define, em princípio, pela assiduidade a uma entidade determinada, - a literatura (ZILBERMAN, 2009, p. 30).

Assim, na escola, o contato com a leitura, acontece apenas como suporte para efetivação de outras atividades. Por vezes, esse ato mecânico e formalizado, torna-se enfadonho, cansativo e, por conseguinte, visto pelo aluno como uma atividade sem sentido. Dessa forma torna-se desestimulado ao ler para esse fim e sua formação como leitor fica prejudicada, pois, verá a leitura como mais uma atividade rotineira. De acordo com Zilberman (2009), para que o letramento literário requer tempo, contato direto e constante com o texto literário. Que a escola ofereça oportunidades para o aluno e ofereça 


\section{Gislene de Sousa Oliveira Silva \& Selma Martines Peres}

uma biblioteca, com acervo literário incentivador, ou banco de textos em sala de aula ou na sala de leitura, onde o aluno possa manusear obras literárias, enfim, que a literatura faça parte do currículo do ensino da língua, dentro e fora da sala de aula. Sugere que o professor possa utilizar de metodologias e práticas que ajudem a concretizar o letramento literário.

A primeira delas é o estabelecimento de uma comunidade de leitores na qual se respeitem a circulação dos textos e as possíveis dificuldades de respostas às leituras deles. Essa medida simples é importante, porque assegura a participação ativa do aluno na vida literária e, por meio dela, a sua condição de sujeito. Para efetivar essa comunidade, o professor pode lançar mão de estratégias como grupos de estudo, clubes de leitura e outras formas de associação entre os alunos que permitam o compartilhamento de leituras e outras atividades coletivas relacionadas ao universo da literatura (ZILBERMAN, 2009, p.74-75).

A autora ainda destaca a relevância também de ampliar e consolidar a relação do aluno com a literatura, na exploração de textos literários, da tradição oral, dos meios de comunicação de massa, de manifestações artísticas, para que o aluno perceba a literatura como parte deles e eles como partícipes na literatura. Assim, é importante que o professor aproveite os meios de comunicação próximos ao aluno, como por exemplo, a internet, porém, não deixando de fazer interferências críticas na formação leitora desse aluno, em sua educação literária e aprendizagem da cultura literária. A prática da escrita na interação com a literatura também é destacada pela autora como forma de oferecer ao aluno a oportunidade de se exercitarem com as palavras, a saber, exercícios de paráfrase, paródia e outros que promovam um diálogo criativo do aluno com a literatura. Acima de tudo, deve ter como objetivo último a interação verbal intensa e o (re) conhecimento do outro e do mundo que são proporcionados pela experiência da literatura. É isso que torna a literatura tão importante para o desenvolvimento cultural do ser humano. É isso que significa apropriar-se da literatura como construção literária de sentido. É isso que constitui o letramento literário dentro e fora da escola.

Importante que a escola seja um espaço para a preservação da essência de arte que a literatura tem, por isso é tão preocupante reduzi-la a um mero mecanismo de memorização de técnicas de alfabetização, ou atividades de ortografia e outros aspectos formais da língua e ainda, utilizados como exercício de simples leitura como se bastasse

Educação, Psicologia e Interfaces, Volume 3, Número 1, p. 43-60, Janeiro/Abril, 2019. 
o ato de ler para adquirir conhecimento e compreender o contexto e função do texto literário lido. Perde-se com essas atividades mecânicas, o sentido estético, criativo e imaginário da literatura. Com isso, a formação do leitor literário fica comprometida, desde seus primeiros contatos, na escola, com os livros literários.

Na maioria das vezes, o docente tem como principal instrumento de trabalho em sala de aula, o livro didático e estes, na atualidade, trazem diversos tipos de textos, dentro de diferentes gêneros, mas, a literatura fica prejudicada com esta realidade, pois, apresentam-se no livro didático, apenas pequenos recortes de textos literários. De acordo com isto, Zilberman (2003), afirma que a leitura de fragmentos de textos literários presentes no livro didático não forma. É no livro, onde materialmente se apresenta a literatura, ou seja, a obra literária em sua integridade. E assim, a oportunidade de apresentar o texto completo, do livro do qual foi retirado o excerto, passa despercebido pelo professor como momento de instigar a leitura. Segundo Cosson (2014, p.15), alguns livros didáticos que antes se constituíam de fragmentos de textos literários, hoje se perdem entre receitas culinárias, regulamentos, roteiros, bulas de remédio e textos jornalísticos que são esmagadora maioria e servem à função de formar um leitor competente.

Essa nova organização do livro didático está de acordo com as teorias mais recentes do ensino de língua, as quais pressupõem que o leitor competente é formado por meio do contato com textos de uso social variado. Além disso, tendem a considerar que o texto literário, por seu caráter artístico, não apresenta a regularidade necessária para servir de modelo ou exemplo para o ensino da escrita, logo devendo ceder lugar a outros tipos de texto que apresentem tais características (COSSON, 2014, p.15).

O autor ressalta que a literatura vem perdendo espaço na escola e em sala de aula. Outros gêneros literários são privilegiados em nome da formação do leitor. Porém, essa percepção de desaparecimento ou deslocamento da literatura talvez se explique pelo fato de da associação, a todo o momento, da leitura e da escrita, ao livro. Dessa maneira, tornase evidente a necessidade de resgate da literatura, levando em consideração a nova forma de que esta vem sendo difundida em diferentes formatos e veículos, usualmente em composição com outra manifestação artística, a saber, através da canção popular, do filme como transposição de um romance para as telas, histórias em quadrinhos, com a ampliação de seus gêneros, como os mangás e os graphic novels. Conforme o autor, os 
HQs estão reconhecidos como narrativas que possuem os mais variados recursos imagéticos e textuais - "avatares da literatura. O mais recente é a chamada literatura eletrônica compreendendo obras que se valem dos recursos digitais para compor textos (...)" (COSSON, 2014, p.18). E destaca ainda que,

\begin{abstract}
Nessa nova literatura, as marcas mais evidentes são o fragmento ou a fragmentação tal como possibilitada pelo hipertexto; a interação, que aproxima o texto literário do jogo e da criação conjunta, apagando ou tornando menos nítidas as posições de leitor e autor; a construção textual em camadas superpostas e multimodais, como resultado da exploração dos muitos recursos disponibilizados pelo meio digital (COSSON, 2014 p.18).
\end{abstract}

Cosson chama a atenção sobre o papel da escola diante das variedades de gêneros e da relevância do resgate da literatura como parte do processo de formação do leitor, considerando que a atividade de ler trata-se de um diálogo com o passado, que cria vínculos, estabelece laços entre o leitor e o mundo, e os outros leitores. Segundo ele, a literatura dialoga com a modernidade, com o tecnológico, como livros eletrônicos, os ebooks e estão presentes nas adaptações de obras literárias para a televisão ou para o cinema, na internet em sua facilidade de acesso, como as bibliotecas virtuais e obras em domínio público, no cenário de jogo de computador, com romances adaptados para filmes e/ou minisséries.

Essa variedade de oportunidades de leitura, contato e interatividade, com diversificados gêneros textuais, dentre eles, a leitura literária, são imprescindíveis para a formação do leitor. Em relação a isto, Lajolo (2000, p.53) afirma que, a relação de interatividade depende da maturidade do leitor, adquirida no decorrer de leituras e muitas outras leituras. "Leitor maduro é aquele para quem cada nova leitura desloca e altera o significado de tudo o que já leu, tornando mais profunda sua compreensão dos livros, das gentes e das vidas" (LAJOLO, 2000, p.53).

Nesse sentido, a autora caracteriza como leitor maduro o sujeito capaz de adquirir conhecimento através das leituras que fez da associação destas com cada leitura recente. Refletindo sobre isto, percebo nesse leitor, a habilidade de aproveitar das situações de leitura e interação com autor e texto para potencializar sua compreensão de leituras futuras, com isso aprimora-se como leitor e como sujeito ativo no meio em que vive. Nessa relação, ler significa "ser questionado pelo mundo e por si mesmo, significa 
construir respostas que integram parte das novas informações ao que já se é." (FOUCAMBERT, 1994, p.5).

Torna-se evidente atentar-se para o fato de que o leitor tem papel ativo no processo de leitura, situação distante de ser apenas decodificador dos códigos da língua. Para tanto, é propósito que o leitor consiga relacionar o que lê, com experiências já vivenciadas por ele. De acordo com Chartier (2011, p.116), "Ler é fazer-se ler e dar-se a ler. (...) falar sobre o que, talvez, não se chegue a dizer, de outro modo e mais claramente. (...) Permitir uma emergência daquilo que está escondido.”

Percebe-se, dessa maneira que, cada leitor, ao longo de suas experiências traz consigo, a cada nova leitura, uma biblioteca particular, memórias de outras leituras e de outras situações vivenciadas, condizentes com sua cultura, forma de ver o mundo e de acordo com o segmento social ao qual pertence (GOULEMOT, 2011, p.116). Portanto, nesse processo adquire cada vez mais, outras experiências, para contribuírem com sua formação leitora. Nos dizeres de Orlandi (1995, p.69),

Todo leitor tem sua história de leituras. O conjunto de leituras feitas por um leitor específico é um aspecto relevante que configura a sua compreensibilidade (capacidade de compreender). As leituras já feitas por um leitor específico dirigem - podem alargar ou restringir a compreensão do texto. Essa é a contrapartida, para o leitor, da sedimentação histórica de sentidos e do fato de que todo texto tem relação com outros (intertextualidade) (ORLANDI, 1995, p.69).

Sendo assim, de acordo com Kleiman (2002), a leitura é um processo interativo, entre os atores envolvidos, a saber, autor-leitor-texto e também, entre o leitor e diferentes textos, quando, para construir sentido em determinada leitura, associa e interage com o conhecimento adquirido em outras leituras e outras vivências, num exercício de descoberta. Nesta relação, o indivíduo estabelece conexões entre aquilo que lê e suas vivências, para construir sentidos. À medida que esta atividade se torna frequente, mais experiências são acrescentadas. Sendo assim, o sujeito adquire mais habilidade para futuras leituras, com a possibilidade de melhorar a interação com aquilo que lê.

Essa é a realidade em que está inserido sujeito, na escola, desde as séries iniciais. A leitura é um processo de compartilhamento, uma competência social e uma das funções da escola que Cosson (2014) destaca é a de constituir-se como um espaço onde se aprende a partilhar, a compartilhar, a processar a leitura. Ler, para o autor, consiste em produzir sentidos por meio do diálogo. Um diálogo que se trava com o passado. 
A literatura utilizada como pretexto para o trabalho com aspectos formais da língua não proporciona o diálogo sobre o texto, o partilhar do que está escrito com o que se vive, o compartilhar de experiências culturais ao longo da história da humanidade, o diálogo entre o passado e o presente, a reflexão, a formação de sentidos, o desenvolvimento da competência individual e social. Há de se considerar o leitor, o autor, o texto e o contexto.

Assim como os demais gêneros, a literatura ocupa um relevante lugar na formação do leitor e cabe à escola apresentá-la aos alunos, desde as séries iniciais do Ensino Fundamental, pois como discutimos acima, a leitura literária faz parte dos bens culturais da humanidade e de sua história, portanto, cabe o respeito de ser trabalhada como um gênero em si, para fruição, reconhecimento da estética da linguagem, do momento em que o indivíduo pode interagir e refletir com o outro e com suas próprias concepções, atitudes e modo de ver e sentir o mundo, a sociedade em que está inserido.

\section{DESAFIO NA FORMAÇÃO DO LEITOR}

A literatura hoje, segundo o que discutimos, ocupa um papel de pretexto para outros fins na escola e não é valorizada como um gênero e suas particularidades. Leitura literária utilizada como apenas um "motivo" primeiro para destacar conteúdos a serem trabalhados, memorizados e aprendidos. Portanto, esse cenário precisa ser mudado, pois, a leitura literária é parte integrante do rol de gêneros a serem discutidos em sala de aula e a escola ocupa esse espaço de socialização do conhecimento e dos bens culturais produzidos pela humanidade.

De acordo com Machado (2002), a escola é uma das instituições que reforçam e legitimam os bens culturais e tem como papel o de socialização dos bens culturais, portanto, não se pode admitir que os alunos saiam da escola sem terem sido iniciados nas formas de letramento literário, lendo poemas, contos, novelas, romances, entre outros e ainda (e por que não) ousar instigando-os à escrita literária. Trata-se de um desafio diante das atuais concepções de leitura e, principalmente da leitura literária, no contexto escolar. Assim, Machado (2002, p. 71) coloca a leitura literária no mesmo patamar de relevância que os demais gêneros, na escola.

A leitura literária convive com inúmeros outros tipos de leitura, entre elas aquelas voltadas para as necessidades práticas da vida cotidiana

Educação, Psicologia e Interfaces, Volume 3, Número 1, p. 43-60, Janeiro/Abril, 2019. 
(...) mas ela instaura um tipo de pacto com o leitor que a distancia das outras práticas sociais "letradas". (...) Esse pacto se dá - quando se dá - via experiência estética, uma experiência na linguagem da invenção, do jogo simbólico que busca representar realidades não percebidas pela linguagem da comunicação usual, corriqueira. A sua natureza é ficcional e o conhecimento na leitura literária chega-nos através do envolvimento emocional, sensível, de participação e fruição no ato de ler (MACHADO, 2002, p. 71).

Dessa maneira, para a formação do leitor, a leitura literária deve ocupar também um espaço considerável, principalmente no ambiente escolar, pois, a escola tem esse papel de destaque e de essencialmente instigar essa formação e iniciá-la de forma a despertar, cada vez mais (e desde as séries iniciais) o interesse e o gosto pela leitura.

Nos dizeres de Cosson (2014), por meio da leitura da literatura tem-se acesso a uma diversidade de textos, com multiplicidade de formas e pluralidade de temas. A literatura é mais linguagem, é o mundo com palavras e não tem outro limite que a capacidade do homem de significar. Incorporam de maneira única os diversos discursos e estruturas textuais de uma sociedade. É parte integrante do aprendizado permanente da leitura, como atividade instigante e incentivadora do interesse dos alunos para, cada vez mais, apreender o conhecimento e poder refletir, questionar, participar socialmente da comunidade em que vive, de forma crítica e ciente do seu papel. A leitura vista pelo sujeito como fonte de saber e como forma de adquirir conhecimento. Ser leitor é mais do que fruir um livro de ficção ou se deliciar com as palavras exatas da poesia. É também posicionar-se diante da obra literária, identificá-la, questioná-la e expandir os sentidos. Esse aprendizado, que é tornar-se crítico, “(...) não se faz sem um encontro pessoal com o texto enquanto experiência estética, e é isso que se denomina letramento literário" (COSSON, 2006, p. 115).

Assim, pode-se afirmar a respeito da relevância do trabalho com a leitura literária na formação do leitor que possa apreciar a leitura, interagir e compreender, produzir sentidos e ser capaz de adquirir e produzir o próprio conhecimento, a fim de ser um sujeito ativo, atuante e participativo, no que concerne aos aspectos individuais e sociais de seu desenvolvimento pessoal e na sociedade em que está inserido. A formação do leitor nos pressupostos discutidos neste texto trata-se, portanto, de um grande desafio, pois será necessário refletir sobre a prática, conceitos, atitudes e posicionamentos em relação à formação leitora do sujeito, os benefícios da leitura literária, bem como a relevância do resgate da leitura, com o propósito da formação crítica do indivíduo. 
Em relação a isto, Zilberman (2009, p.29), aponta como caminho, "resgatar a leitura, recuperando seu teor revolucionário". De acordo com a autora, resgatar a leitura que consiga provocar o pensar sobre si mesmo, seu lugar no mundo, em sociedade, no espaço da sua casa, na roda de amigos, e ainda perceber o que ouve ou vê, o que outros falam ou pregam, e distinguir sua opinião daquilo que os outros querem inculcar-lhe. $O$ mais relevante é que o sujeito perceba-se como partícipe ativo onde quer que esteja.

De acordo com Soares (1998), a responsabilidade de quem trabalha com a leitura é, principalmente a formação do senso crítico do leitor e isto exige que, primeiramente, a postura de quem auxilia na formação do leitor, seja crítica e consciente das relações sociais e do indivíduo. Geraldi (2012, p.40) corrobora com estas afirmativas ao considerar que, antes de qualquer coisa,

Toda e qualquer metodologia de ensino articula uma opção política que envolve uma teoria de compreensão e interpretação da realidade, com mecanismos utilizados em sala de aula. Assim, os conteúdos, o enfoque que se dá a eles, as estratégias de trabalho com os alunos, a bibliografia utilizada, o sistema de avaliação, o relacionamento com os alunos, tudo corresponderá, nas atividades concretas de sala de aula, ao caminho pelo qual se optou (GERALDI, 2012, p.40).

Segundo o autor, as escolhas pedagógicas na escola refletem posicionamentos políticos dos envolvidos e responsáveis por toda e qualquer ação frente ao sujeito. Britto (2012, p.56) afirma que as atividades na escola têm relevante objetivo de incitar o indivíduo a "compreender criticamente a realidade e construir uma nova racionalidade." Assim, a valorização do sujeito e sua individualidade são significativas, pois, é a partir da consciência de si mesmo e do lugar ocupado na sociedade, que poderá formar opiniões e agir com atitude. Esses momentos requerem um ambiente de encontros e desencontros, participação, discussões, contradições, impactos, descobertas e curiosidades. "Quem lê o faz com toda a sua carga pessoal de vida e experiência, consciente ou não dela, e atribui ao lido as marcas pessoais de memória, intelectual e emocional" (YUNES, 2003, p.10). Dessa forma, subentende-se que, na leitura, o indivíduo tem a oportunidade de se descobrir.

Diante das afirmativas de Geraldi (2012), a prática na escola está impregnada por escolhas políticas, a partir de parâmetros muitas vezes nem percebidos. A educação e a leitura sempre estiveram "a favor de poucos", afirma Castrillon (2011, p.65). Assim, as concepções de ensino da leitura estão também, arraigadas em interesses de uma minoria,

Educação, Psicologia e Interfaces, Volume 3, Número 1, p. 43-60, Janeiro/Abril, 2019. 
visto que, distanciam o sujeito e o colocam, cada vez mais, em uma posição passiva diante do texto.

A utilização do livro por pessoas privilegiadas o estabelece como um segredo do qual somente eles são os 'verdadeiros' intérpretes. Levanta entre o texto e seus leitores uma fronteira que para ultrapassar somente eles entregam os passaportes [...] Deste ponto de vista, o sentido 'literal' é o sinal e o efeito de um poder social, o de uma elite (CERTEAU, 2014, p.243).

A partir das considerações do autor, infere-se que é de fundamental importância repensar as concepções acerca da educação e, consequentemente, a respeito do ensino da leitura. Em algum momento, "tanto a escola como a leitura devem tomar partido por uma transformação social" (CASTRILLON, 2011, p.65). Depreende-se que as mudanças serão possíveis, desde que o foco do ensino da leitura seja a conscientização do sujeito e do seu poder de ação, perante esse processo.

São, portanto pertinentes, os dizeres, sobre o trabalho com a leitura na escola, apresentados por Soares (2008, p.33).

é função e obrigação da escola dar amplo e irrestrito acesso ao mundo da leitura, e isto inclui a leitura informativa, mas também a leitura literária; a leitura para fins pragmáticos, mas também a leitura de fruição; a leitura que situações da vida real exigem, mas também a leitura que nos permita escapar por alguns momentos da vida real (SOARES, 2008, p.33).

Ao indicar que o sujeito tenha acesso ao mundo da leitura, a autora sugere dinamicidade neste trabalho, com objetivo de ocasionar uma visão ampla e significativa das especificidades da leitura. Desse modo, a formação do leitor é um processo complexo que requer planejamento. Vale lembrar que isto "demanda muito esforço por parte do sujeito, pois, nem sempre a leitura será uma atividade agradável”, pondera Britto (2012, p. 45). O autor destaca que é necessário o entusiasmo em relação à leitura, assim como, o indivíduo se conhecer e conhecer as suas necessidades. Segundo ele, "importa que a pessoa saiba o que faz, sendo senhora da ação intelectual.” (BRITTO, 2012, p. 45). Dialogando com o exposto, Kleiman (2002, p. 35) faz os seguintes esclarecimentos:

Cabe notar que a leitura que não surge de uma necessidade para chegar a um propósito não é propriamente leitura; quando lemos porque outra pessoa nos manda ler, como acontece frequentemente na escola, estamos apenas exercendo atividades mecânicas que pouco têm a ver com significado e sentido.

Educação, Psicologia e Interfaces, Volume 3, Número 1, p. 43-60, Janeiro/Abril, 2019.

ISSN: 2594-5343. DOI: https://doi.org/10.37444//issn-2594-5343.v3i1.140 
Fica claro que a autora critica o ensino da leitura planejado a partir de suposições do que seja necessidade para o sujeito. Sendo assim, o indivíduo não percebe finalidade no que é proposto e fica alheio. Estas práticas comprometem o envolvimento do sujeito em sua formação como leitor, visto que lhe é negada a oportunidade de participação e diálogo com a leitura.

\section{CONSIDERAÇÕES FINAIS}

Diante do que fora discutido conclui-se que seja relevante uma postura de ensino da leitura, que tenha como princípio, a formação de um sujeito que perceba e valorize a busca pelo conhecimento, como atividade necessária ao longo da vida. Com esta finalidade, o trabalho com a leitura requer um olhar para o sujeito como um elemento essencial no processo de sua própria formação leitora. E ainda, que considere o sujeito capaz de interagir com a leitura e construir sentidos significativos para si mesmo, e que perceba a importância do diálogo com a leitura, para o senso crítico e empoderamento.

\section{REFERÊNCIAS BIBLIOGRÁFICAS}

BRITTO, Luiz Percival Leme. Inquietudes e desacordos: a leitura além do óbvio. Campinas, SP: Mercado das Letras, 2012.

BRITTO, Luiz Percival Leme. Leitura e política. In: MACHADO, Maria Zélia Versiani et al. (Orgs.). Escolarização da leitura. Belo Horizonte: Autêntica, 1999.

CASTRILlÓN, Silvia. O Direito de Ler e Escrever. Trad. Marcos Bagno. São Paulo: Pulo do Gato, 2011.

CERTEAU, Michel de Certeau. A Invenção do Cotidiano - Artes de fazer. Trad. Ephraim Ferreira Alves. 22 ed. Petrópolis: Vozes, 2014.

CHARTIER, Roger. Práticas da Leitura. Trad. Cristiane do Nascimento. 5 ed. São Paulo: Estação Liberdade, 2011.

COSSON, Rildo. Círculos de leitura e Letramento Literário. São Paulo: contexto, 2014.

COSSON, Rildo. Letramento literário: teoria e prática. São Paulo: Contexto, 2006. FOUCAMBERT, Jean. A leitura em questão. Trad. Bruno Charles Magne. Porto Alegre: Artes Médicas, 1994.

FREIRE, Paulo. A importância do ato de ler: em três artigos que se completam. São Paulo: Autores Associados: Cortez, 1989.

Educação, Psicologia e Interfaces, Volume 3, Número 1, p. 43-60, Janeiro/Abril, 2019. 
GERALDI, J. W. (Org.). O texto na sala de aula. 3 ed. São Paulo: Anglo, 2012.

GOULEMOT, Jean Marie. Da leitura como produção de sentidos. In: CHARTIER, Roger. Práticas da Leitura. Trad. Cristiane do Nascimento. 5 ed. São Paulo: Estação Liberdade, 2011.

KLEIMAN, Ângela. Texto e leitor: Aspectos cognitivos da leitura. 5 ed. São Paulo: Pontes, 2002.

LAJOLO, Marisa. Do mundo da leitura para a leitura do mundo. São Paulo: Ática, 2000.

MACHADO, Maria Zélia Versiani. Literatura na Escola: entre as escolhas dos alunos e as escolhas para os alunos. In: FREITAS, M.T.A; COSTA, S.R.(org) Leitura e Escrita na Formação de Professores. São Paulo: Musa, 2002.

MARTINS, M. H. O que é leitura? 19 ed. São Paulo. Brasiliense, 1994.

ORLANDI, Eni Pulcinelli. Leitura: de quem. Para quem? In: ABREU, Márcia (Org.).

Leitura, história e história da leitura. Campinas, SP: Mercado das Letras, 1995.

PAULINO, G.; COSSON, R. Letramento Literário: para viver a literatura dentro e fora da escola. In: ZILBERMAN, R; RÖSING. T. Escola e Leitura: velha crise, novas alternativas. São Paulo: Global, ALB. 2009.

SILVA, Ezequiel Theodoro da. $O$ ato de ler: fundamentos psicológicos para uma nova pedagogia da leitura. 7 ed. São Paulo: Cortez, 1996.

SILVA, Ezequiel Theodoro da. Elementos de pedagogia da leitura. 3 ed. São Paulo: Martins Fontes, 1998.

SOARES, Magda. Letramento e alfabetização: as muitas facetas. Revista Brasileira de Educação, nº 25, jan./abr. 2004.

SOARES, Magda. Alfabetização e Letramento. 5 ed. São Paulo: Contexto, 2008.

SOARES, Magda. Alfabetização e Letramento. 6 ed. São Paulo: Contexto, 2011.

SOARES, Magda. As condições sociais da leitura: uma reflexão em contraponto. In: ZILBERMAN, Regina; SILVA, Ezequiel (Orgs). Leitura e perspectivas interdisciplinares. 4 ed. São Paulo: Ática, 1998.

SOARES, Magda. Letramento: Um tema em três gêneros. 2 ed. Belo Horizonte: Autêntica, 2000.

YUNES, Eliana; OSWALD, Maria Luiza. A experiência da leitura. São Paulo: Loyola, 2003.

ZILBERMAN, R. (Org.). Leitura: perspectivas interdisciplinares. São Paulo: Ática, 2003. 
ZILBERMAN, R. A escola e a leitura da literatura. In: ZILBERMAN, R. et al. (Orgs.). Escola e Leitura: velha crise, novas alternativas. São Paulo: Global, ALB, 2009.

\section{Credenciais das autoras}

SILVA, Gislene de Sousa Oliveira Silva. Mestra em Educação - Universidade Federal de Goiás - Regional Catalão. Professora na Seduce/Goiás e Prefeitura Municipal de Catalão/Goiás. E-mail: gsoliveira_2007@yahoo.com.br.

PERES, Selma Martines. Doutora em Educação pela UFSCar - Universidade Federal de São Carlos (2006) Docente da UFG - Universidade Federal de Goiás - Regional Catalão, da UAEE - Unidade Acadêmica Especial de Educação e do PPGEDUC - UFG/CAC Programa de Pós-Graduação em Educação. Catalão, Goiás, Brasil. E-mail: selmamartines@uol.com.br

Endereço para correspondência: Gislene de Sousa Oliveira Silva. Rua Antônio Salviano, 580. Residencial Estrela - Catalão-GO. E-mail: gsoliveira_2007@yahoo.com.br.

Como citar este artigo (Formato ABNT): SILVA, Gislene de Sousa Oliveira; PERES, Selma Martines. Prelúdios acerca da leitura e a formação do sujeito. Educação, Psicologia e Interfaces, v. 3, n.1, p. 43-60, 20119. DOI: https://doi.org/10.37444/issn2594-5343.v3i1.140

Recebido: 04/01/2019.

Aceito: 20/03/2019. 